\title{
Individual differences in regulatory focus predict neural response to reward
}

\section{Matthew A. Scult, Annchen R. Knodt, Jamie L. Hanson, Minyoung Ryoo, R.} Alison Adcock, Ahmad R. Hariri \& Timothy J. Strauman

To cite this article: Matthew A. Scult, Annchen R. Knodt, Jamie L. Hanson, Minyoung Ryoo, R. Alison Adcock, Ahmad R. Hariri \& Timothy J. Strauman (2016): Individual differences in regulatory focus predict neural response to reward, Social Neuroscience, DOI: $\underline{10.1080 / 17470919.2016 .1178170}$

To link to this article: http://dx.doi.org/10.1080/17470919.2016.1178170

Accepted author version posted online: 14

Apr 2016.

Published online: 30 Apr 2016.

Submit your article to this journal $\asymp$

Llll Article views: 68

View related articles $\nearrow$

View Crossmark data $\nearrow$

Citing articles: 1 View citing articles $\widetilde{ }$ 


\title{
Individual differences in regulatory focus predict neural response to reward
}

\author{
Matthew A. Scult $\mathbb{1}^{a}$, Annchen R. Knodta, Jamie L. Hanson ${ }^{a, b}$, Minyoung Ryoo ${ }^{a}$, R. Alison Adcockc, \\ Ahmad R. Hariria and Timothy J. Strauman ${ }^{a}$ \\ aDepartment of Psychology \& Neuroscience, Duke University, Durham, NC, USA; ${ }^{b}$ Center for Developmental Science, University of North \\ Carolina Chapel Hill, Chapel Hill, NC, USA; 'Department of Psychiatry and Behavioral Sciences, Duke University, Durham, NC, USA
}

\begin{abstract}
Although goal pursuit is related to both functioning of the brain's reward circuits and psychological factors, the literatures surrounding these concepts have often been separate. Here, we use the psychological construct of regulatory focus to investigate individual differences in neural response to reward. Regulatory focus theory proposes two motivational orientations for personal goal pursuit: (1) promotion, associated with sensitivity to potential gain, and (2) prevention, associated with sensitivity to potential loss. The monetary incentive delay task was used to manipulate reward circuit function, along with instructional framing corresponding to promotion and prevention in a within-subject design. We observed that the more promotion oriented an individual was, the lower their ventral striatum response to gain cues. Follow-up analyses revealed that greater promotion orientation was associated with decreased ventral striatum response even to no-value cues, suggesting that promotion orientation may be associated with relatively hypoactive reward system function. The findings are also likely to represent an interaction between the cognitive and motivational characteristics of the promotion system with the task demands. Prevention orientation did not correlate with ventral striatum response to gain cues, supporting the discriminant validity of regulatory focus theory. The results highlight a dynamic association between individual differences in self-regulation and reward system function.
\end{abstract}

\section{ARTICLE HISTORY}

Received 4 August 2015

Revised 29 February 2016

Published online

3 May 2016

\section{KEYWORDS}

Reward; individual differences; regulatory focus; monetary incentive delay; fMRI

\section{Introduction}

What motivates people to pursue their personal goals varies from individual to individual as well as from one situation to another. For example, one person might be motivated to do well on a presentation at school by a desire to impress her teacher, while another might be motivated by a desire to not embarrass herself in front of the class. Furthermore, behavioral science has long known that the same desired end state can be attained by using different strategies (Higgins, 1997), such as repeatedly practicing the presentation to increase one's confidence versus not staying up late the night before in order to be fully rested. At the same time, there is a substantial literature in cognitive and social neuroscience elucidating the neural circuitry associated with goal pursuit and choice (Knutson \& Greer, 2008). An important challenge for research is to integrate these two levels of analysis. In addition, a more comprehensive model of the mechanisms of personal goal pursuit could lead to more effective incentive structures to promote a wide range of educational, work and clinical initiatives.
There are a number of behavioral theories that provide compelling models for the psychological aspects of personal goal pursuit. Regulatory focus theory (RFT; Higgins, 1998) postulates two cognitive/motivational systems for personal goal pursuit, promotion and prevention, which are centered around attaining positive end states via sensitivity to potential gain ("making good things happen") and via sensitivity to potential loss ("keeping bad things from happening"), respectively. Individuals with a dominant promotion orientation tend to emphasize aspirations and accomplishments and to prefer situations where there are opportunities to gain or achieve, while individuals with a dominant prevention orientation tend to emphasize responsibility and safety and to prefer situations and strategies involving minimizing loss (Crowe \& Higgins, 1997). These differences are manifested in distinct patterns of affect and behavior in domains as diverse as mood regulation (Vieth et al., 2003), work performance (Lanaj, Chang, \& Johnson, 2012), and political decisionmaking (Boldero \& Higgins, 2011). As such, RFT provides a model for both momentary and chronic influences on the "psychological situation"- that is, the lived experience 
(Lewin, 1946)—underlying specific instances of goal pursuit.

Individual differences in regulatory focus have been shown to be stable over time and to predict differences in goal pursuit strategy use (Higgins, Roney, Crowe, \& Hymes, 1994; Strauman, 1996). For example, in behavioral experiments, participants with a dominant promotion focus tend to generate a greater number of hits and fewer errors of omission, while individuals with a dominant prevention focus tend to make more correct rejections and fewer errors of commission (Crowe \& Higgins, 1997; Förster, Higgins, \& Bianco, 2003). In combination with reward-relevant genotypic variability, this aspect of promotion orientation has been shown to result in a greater positive response bias for individuals with higher promotion success (Goetz, Hariri, Pizzagalli, \& Strauman, 2013). Additionally, an individual's regulatory focus has been shown to interact with explicit incentives in a predictable manner. For example, greater promotion orientation has been associated with improved performance on an anagram task where participants had the opportunity to win money, while greater prevention orientation was associated with improved performance on the same task when participants had to avoid losing money (Shah, Higgins, \& Friedman, 1998). These and similar studies suggest the importance of understanding the interaction of trait differences in chronic regulatory focus and momentary instructional framing, but how these state and trait differences interact with the brain's reward circuitry during goal pursuit is yet unknown.

Published studies to date have focused on investigating the neural correlates of regulatory focus itself rather than the interaction between regulatory focus and reward. The consistent differences between promotion and prevention observed in behavioral studies (for a review, see Molden, Lee, \& Higgins, 2008) suggest that distinct neural correlates would be found for those two motivational orientations, and indeed reliable differences have been observed. One study using idiographic personal goal stimuli as primes found that individual differences in promotion orientation were related to orbitofrontal cortex activation in the left hemisphere during promotion goal priming (Eddington, Dolcos, Cabeza, Krishnan, \& Strauman, 2007), consistent with earlier reports of resting EEG laterality differences between promotion and prevention (Amodio, Shah, Sigelman, Brazy, \& Harmon-Jones, 2004). A follow-up study using implicit goal priming found activation in several reward-related regions such as caudate, thalamus, and cingulate that correlated with individual differences in promotion orientation during promotion priming. In contrast, during prevention priming, occipital cortex, superior parietal lobule, and precuneus were related to prevention orientation (Strauman et al., 2013). These studies collectively raise the possibility of a role for regulatory focus in the modulation of rewardrelated neural circuitry, particularly in the context of promotion focus. In particular, RFT provides a template by which to hypothesize how promotion and prevention focus, both as situational factors and as individual differences, could influence the goal pursuit process.

A widely used paradigm for studying reward responsivity is the monetary incentive delay (MID) task (Knutson, Westdorp, Kaiser, \& Hommer, 2000). In this task, subjects see a cue that is associated with the potential to win or lose a given monetary amount; subjects then have to respond within a given time window in order to gain or avoid losing the money in that trial. The MID task reliably elicits patterns of activation during gain and loss anticipation that are consistent over time (Knutson \& Greer, 2008; Wu, SamanezLarkin, Katovich, \& Knutson, 2014). In particular, metaanalysis of the MID task has found that gain anticipation is selectively associated with activation in the ventral striatum (VS), especially the nucleus accumbens (Knutson \& Greer, 2008).

Given that the MID task requires subjects to respond to stimuli involving potential gains and losses, we used RFT to generate hypotheses regarding differences between promotion and prevention orientation under conditions of anticipated gain or loss. Of note, the implicit, and sometimes explicitly stated, goal of the MID task is to win money, which can be considered a promotion framing. Nonetheless, in the present study, we manipulated the task instructions to incorporate explicit promotion versus prevention framing in order to detect neural activation patterns associated with promotion versus prevention states on a within-subject basis. We instructed subjects to "try to win as much money as possible"-that is, make good things happen-or to "try to avoid losing as much money as possible"-that is, to keep bad things from happening-on the different MID runs so as to investigate whether promotion or prevention priming, either by itself or in combination with participants' chronic regulatory orientation, would lead to distinguishable patterns of neural response to reward cues.

Given that promotion orientation is characterized by sensitivity to potential gain (Higgins, 1998), and that gain anticipation in the MID task has been associated with VS activation (Knutson \& Greer, 2008), if the MID task is experienced as an opportunity to "make things happen" we should observe an association between individual differences in promotion orientation and VS response. Specifically, based on the RFT literature, it 
was predicted that greater promotion orientation would be correlated with increased activity in the VS to reward-related cues on the MID task. In contrast, we anticipated that individual differences in prevention orientation would not correlate with VS response to reward-related cues. The inclusion of both promotion and prevention focus, as individual differences and within the instructional priming, allowed us to test the discriminant validity of our predictions regarding promotion focus and VS response to reward cues. Lastly, we anticipated that the association between promotion orientation and VS response to reward cues would be most clearly observed under conditions of explicit promotional framing.

\section{Methods}

\section{Participants}

Subjects were recruited via posted flyers and through recontacting participants who had enrolled in previous studies in the lab. Informed consent was obtained for all subjects as approved by the Duke University School of Medicine Institutional Review Board. Exclusion criteria included a standard set of contraindications that would render an individual ineligible for an $\mathrm{fMRI}$ scan for safety reasons. A total of 24 undergraduate students enrolled in the study, 16 females and 8 males. The age of participants ranged from 18 to 22, with a mean of 19.67 (SD = 1.27). Of the 24 subjects, 10 were Caucasian, 8 were Asian, 5 were African-American, and 1 was Hispanic. Subjects were compensated for their time and allowed to keep their winnings from the task.

\section{Questionnaire measures}

Subjects completed demographics questions and a modified version of the regulatory focus questionnaire (RFQ) (Higgins et al., 2001), which measures individual differences in promotion and prevention orientation. The questionnaire consisted of 26 self-report items rated on a five-point scale from "never or seldom/certainly false" to "very often/certainly true." Items are averaged and scores are broken down into four subscales: promotion history, prevention history, promotion success, and prevention success. The first two subscales ask about early life experiences of being oriented toward promotion or prevention by one's parents. The other two subscales ask about an individual's appraisal of their overall success at achieving promotion or prevention-type goals. Sample items include, "My parents encouraged me to try new things" (promotion history), "My parents kept order in our house by having a lot of rules and regulations for me" (prevention history), "I feel like I have made progress toward being successful in life" (promotion success), and "Not being careful enough has gotten me into trouble at times" (prevention success, reverse-scored). The success subscales were employed for our analyses as they have demonstrated test-retest reliability (Higgins et al., 2001).

\section{MID task}

A version of the MID task developed by Knutson et al. (Beck et al., 2009; Knutson et al., 2000) was used in the experiment. During the task, participants are engaged in conditions involving no monetary outcome ("no response trials"), potential reward ("gain trials"), or potential punishment ("loss avoidance trials"). The task consisted of two runs, each with a total of 90 eightsecond trials. A sample trial is diagrammed in Figure 1.

During each trial, participants see a cue $(2 \mathrm{~s})$, wait a variable interval $(2-3 \mathrm{~s})$, and then respond to a white target square, which appears for a variable length of time (40-600 ms) via button press. After another delay (1-2 s), feedback appears ( $2 \mathrm{~s}$ ) indicating whether the participant has won or lost money as well as their cumulative total at that point. Cues consist of circles ( $n=72$, gain trials), squares ( $n=72$, loss avoidance trials), and triangles ( $n=36$, no response trials). Gain cues signal the possibility of winning $\$ 0, \$ 0.20, \$ 1$, or $\$ 5$, denoted by circles with increasing number of horizontal lines inside a circle. Loss cues signal the possibility of losing $\$ 0, \$ 0.20, \$ 1$, or $\$ 5$, denoted by squares with increasing number of horizontal lines inside the square. There are 18 instances of each specific trial type (e.g., possible $\$ 0.20$ gain), along with 36 noresponse trials (indicating that the subject should not respond after they see a triangle cue) for a total of 180 trials. Trial types are pseudo-randomly ordered within each run. In total, each run lasts $12 \mathrm{~min}, 20 \mathrm{~s}$. Participants practiced the task outside the scanner with nine practice trials so that they saw each trial type once in order to minimize later learning effects. At the beginning of the practice, participants were shown a sheet of paper summarizing the outcome contingencies. They were observed during the practice to ensure they were completing the task correctly and asked whether they had any questions. In the scanner, an adaptive algorithm was used that changed the target durations based on past performance, so that subjects would be exposed consistently to an approximately $66 \%$ success rate.

In order to investigate the role of promotion and prevention task framing in goal pursuit within the MID task specifically, participants were instructed with a 


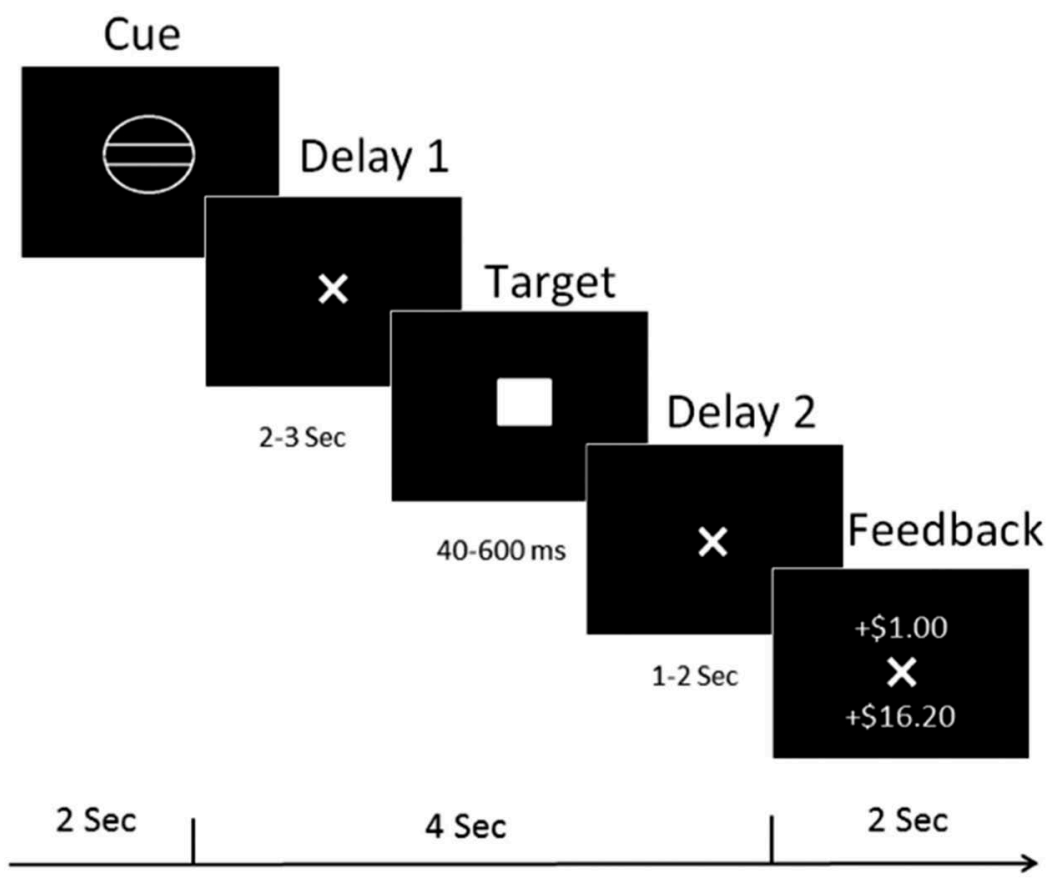

Figure 1. Sample trial from the MID task. During each trial, participants see a cue $(2 \mathrm{~s})$, wait a variable interval (2-3 s), and then respond to a white target square, which appears for a variable length of time (40-600 ms). After another delay (1-2 s), feedback appears (2 s) indicating whether the participant has won or lost money, as well as their cumulative sum.

promotion frame ("the goal on this run is to win as much money as possible") or a prevention frame ("the goal on this run is to avoid losing as much money as possible") before each run; the order of instructions was counterbalanced between subjects. Each participant completed one promotion-framed run and one prevention-framed run.

\section{BOLD fMRI data acquisition}

Each participant was scanned using a research-dedicated GE MR750 3 T scanner at the Duke University - University of North Caroline at Chapel Hill Brain Imaging and Analysis Center. This scanner is equipped with highpower, high-duty-cycle $50 \mathrm{mT} / \mathrm{m}$ gradients at $200 \mathrm{~T} / \mathrm{m} / \mathrm{s}$ slew rate and an 8-channel head coil for parallel imaging at high bandwidth up to $1 \mathrm{MHz}$. A semiautomated highorder shimming program was used to maximize global field homogeneity. To allow for spatial registration of each participant's data to a standard coordinate system, highresolution three-dimensional structural images were acquired in 34 axial slices coplanar with the functional scans [repetition time (TR)/echo time (TE)/flip angle $=7.7 \mathrm{~s} / 3.0 \mathrm{~ms} / 12^{\circ} ;$ voxel size $=0.9 \times 0.9 \times 4 \mathrm{~mm}$; field of view $(\mathrm{FOV})=240 \mathrm{~mm}$; interslice skip $=0$ ]. For the two $12 \mathrm{~min}, 20 \mathrm{~s}$ scans, a series of 34 interleaved axial functional slices aligned with the anterior commissureposterior commissure plane were acquired for whole- brain coverage using an inverse-spiral pulse sequence to reduce susceptibility artifact (TR/TE/flip angle $=2000 \mathrm{~ms}$ / $30 \mathrm{~ms} ;$ FOV $=240 \mathrm{~mm}$; voxel size $=3.75 \times 3.75 \times 4 \mathrm{~mm}$; interslice skip $=0$ ). Two initial radiofrequency excitations were performed (and discarded) to achieve steady-state equilibrium.

\section{BOLD fMRI data analysis}

Preprocessing of all $\mathrm{fMRI}$ data was conducted using Statistical Parametric Mapping 8 (SPM8; www.fil.ion.ucl. ac.uk/spm). Images for each subject were slice-time-corrected, realigned to the first volume in the time series to correct for head motion, spatially normalized into a standard stereotactic space (ICBM_average_151 template) using a 12-parameter affine model (final resolution of functional images $=2 \mathrm{~mm}$ isotropic voxels), and smoothed to minimize noise and residual differences in gyral anatomy with a Gaussian filter set at $6 \mathrm{~mm}$ full-width at half-maximum. Voxel-wise signal intensities were ratio normalized to the whole-brain global mean. A high-pass temporal filter was applied with a cutoff of $128 \mathrm{~s}$.

Variability in single-subject whole-brain functional volumes was determined using the Artifact Recognition Toolbox (http://www.nitrc.org/projects/artifact_detect). Individual whole-brain BOLD fMRI volumes meeting at least one of two criteria were flagged for inclusion as regressors of no interest in determination of task-specific 
effects: (1) significant mean-volume signal intensity variation (i.e., within volume mean signal greater or less than 4 standard deviations of mean signal of all volumes in time series) and (2) individual volumes where scan-to-scan movement exceeded $2 \mathrm{~mm}$ translation or $2^{\circ}$ rotation in any direction. Participants with $>5 \%$ of volumes flagged as outliers were excluded from analyses.

The general linear model of SPM8 was used to conduct an event-related analysis via a two-level procedure. For the first, single-subject level, the nine different cue conditions (four gain, four loss, one no response), delay 1 , target and delay 2 , and five feedback conditions were modeled as separate events. The five feedback conditions were successful gain, unsuccessful gain, successful loss avoidance, unsuccessful loss avoidance, and nonincentive trials. For second-level analyses, the linear contrast images for "gain cues>non-gain" (cir1, cir2, cir3 > cir) and "loss cues > nonloss" (sqr1, sqr2, sqr3 > sqr) were calculated for each subject and used for between-subjects analyses.

A VS region of interest ( $\mathrm{ROI}, 10 \mathrm{~mm}$ spheres around MNI coordinates $x= \pm 12, y=12, z=-10$ ) was constructed using the Talairach Daemon option of the WFU PickAtlas Tool, version 1.04 (Wake Forest University School of Medicine, Winston-Salem, NC, USA). A statistical threshold of $p<0.05$, family-wise error rate correction with $\geq 10$ contiguous voxels across the ROI was applied to the contrast of gain cues $>$ nongain and loss cues $>$ nonloss. Mean BOLD values from significant clusters were extracted using the Volume of Interest tool in SPM8 of the cluster average for significant clusters. These extracted values were then used in a statistical model using IBM SPSS Statistics 22.0 (Chicago, IL, USA).

Whole-brain activity was also examined to confirm that activation corresponded to that found in previous studies (Knutson \& Greer, 2008). Analyses were conducted using a gray matter mask and correction for multiple comparisons was conducted in AFNI's 3dClustSim using cluster-size thresholding based on Monte Carlo simulation. This program creates multiple simulated null data sets from which a distribution of cluster sizes corresponding to a desired corrected $p$-value can be determined. An initial uncorrected statistical threshold of $p<0.001$ was chosen. Based on this threshold, the number of comparisons in our imaging volume and the smoothness of our imaging data, as measured by 3dFWHMx, a minimum cluster size of 91 voxels was required to have a corrected $p \leq 0.05$.

A linear regression model was implemented in SPSS for assessing the correlation between the extracted BOLD signal values and with scores on the promotion success and prevention success subscales.

\section{Results}

\section{Questionnaire results}

For the questionnaire responses, subjects had a mean promotion success score of 4.06 (0.47) and prevention success score of $3.59(0.56)$, which was comparable to values found in prior large-scale studies [promotion $M=3.72$ (0.67); prevention $M=3.29$ (0.86)] (Neubert, Kacmar, Carlson, Chonko, \& Roberts, 2008). The skewness and kurtosis for the RFQ were found to be within an acceptable range (promotion skewness $=0.396$, $\mathrm{SE}=0.50$, kurtosis $=-0.94, \mathrm{SE}=0.97$; prevention skewness $=-0.45, \mathrm{SE}=0.50$, kurtosis $=-0.31$, SE $=0.97)$.

\section{Behavioral results}

Two subjects were excluded due to software malfunction and one fell asleep during the task, leaving a total of 21 subjects who were included in behavioral analyses (14 females, 7 males). Participants' accuracy on the MID task approximated the target hit rate of $66 \%(63.46 \% \pm 3.6 \%)$, and a repeated-measures analysis of variance indicated that there were no significant differences in hit rate among the eight response cue types $(p>0.05)$. On average, a pattern of faster average reaction times was observed for the $\$ 5$ and $\$ 1$ cues relative to the $\$ 0.20$ and $\$ 0$ gain cues. There were no overall differences in reaction time between gain and loss trials.

There was no correlation between promotion success and average reaction time to gain trials $[F$ $(1,19)=1.314, p=0.266, b=0.254]$ or loss trials $[F$ $(1,19)=0.382, p=0.544, b=0.140]$ or between prevention success and average reaction time to gain trials $[F$ $(1,19)=0.010, p=0.922, b=-0.023]$ or loss trials $[F$ $(1,19)=0.139, p=0.714, b=-0.085]$. The null behavioral results are not surprising, however, given that the task and study were designed to maximize neural response to incentives and due to the nature of the adaptive algorithm was not well designed to capture differences in behavioral responses.

Results did not change significantly after controlling for participant sex and race.

\section{Imaging results}

Two additional subjects were excluded from the imaging analyses due to head motion in excess of our predefined threshold, leaving a total of 19 subjects who were included in the imaging analyses. Motion was not correlated with regulatory focus orientation (ps > 0.05). 


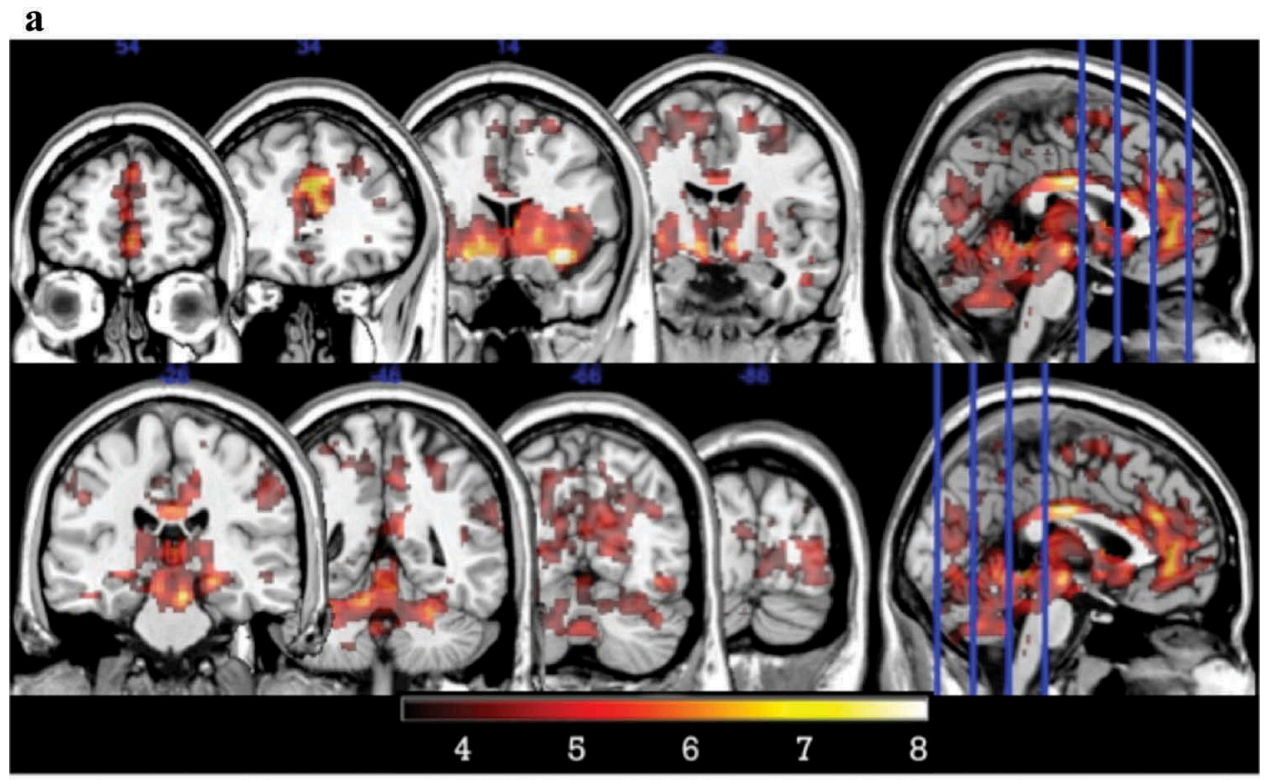

b

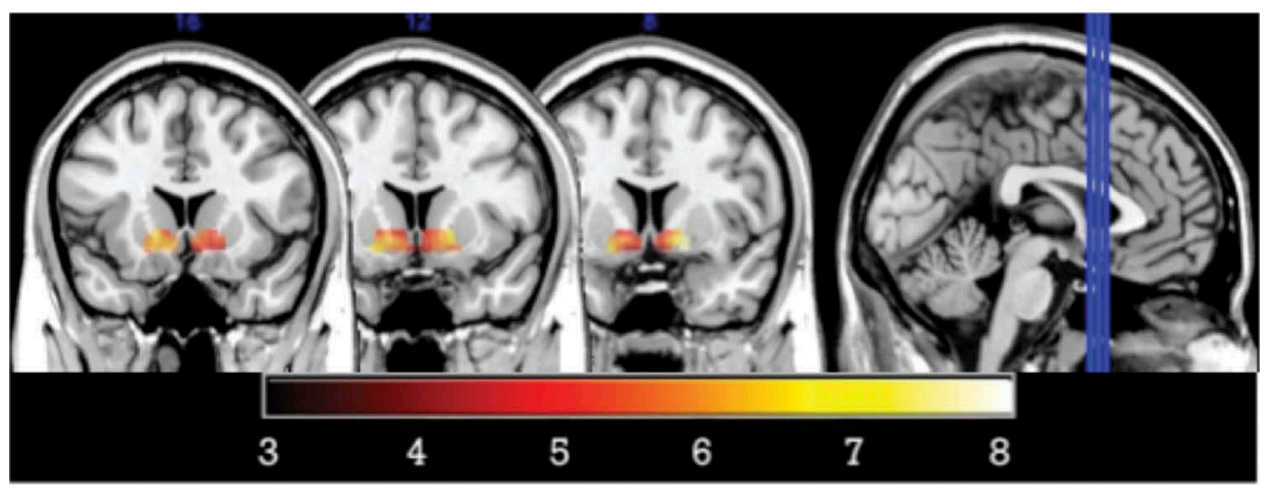

Figure 2. Task-based activation for gain > no gain. (a) Whole-brain activation was similar to that found in previous papers using the MID, indicating the task was implemented effectively ( $p=0.05$ corrected, cluster size $=94$ voxels). (b) Robust activation was found in the ventral striatum ROls used for further analyses (10 mm sphere around $x= \pm 12, y=12, z=-10$ ).

Overall activation during the MID task replicated previous findings (Figure 2), indicating that the task had been properly implemented and that the present sample responded on average in expected ways to the set of cues that are included in the task.

The VS ROI analyses found that promotion success was negatively correlated with VS activation to gain cues [left VS: $F(1,17)=5.119, p=0.037, b=-0.481$, Figure 3(a); right VS: $F(1,17)=3.793, p=0.068$, $b=-0.427]$. The negative correlation indicated that greater self-reported promotion success was associated with decreased VS response to reward cues relative to neutral cues. As expected, no correlation was found between VS response to gain cues and prevention success [left VS: $F(1,17)=0.125, p=0.728, b=0.085$, Figure $3(\mathrm{~b})$; right VS: $F(1,17)=0.834, p=0.374$, $b=0.216]$. As a further check of this specificity, both promotion and prevention success were entered into the same model and it was found that promotion success was associated with VS response to gain while prevention success was not [LVS: $F(1,16)=2.416$, $p=0.121$; promotion $b=-0.478, p=0.046$; prevention $b=0.023, p=0.918$; RVS: $F(1,16)=2.110, p=0.154$; promotion $b=-0.406, p=0.089$; prevention $b=0.164$, $p=0.477]$.

Neither promotion nor prevention was related to VS response to loss [LVS: promotion $F(1,17)=0.473$, $p=0.501, b=-0.164$, Figure $3(\mathrm{c})$; prevention $F(1$, $17)=0.008, p=0.931, b=0.021$, Figure $3(\mathrm{~d})$; RVS: promotion $F(1,17)=0.930, p=0.348, b=-0.228$; prevention $F(1,17)=0.806, p=0.382, b=0.213]$. The promotion and prevention priming at the beginning of each run was not found to have a significant effect on VS reactivity (all $p s>0.05$ ).

Follow-up analyses indicated that the significant effects of promotion success on VS response seemed 

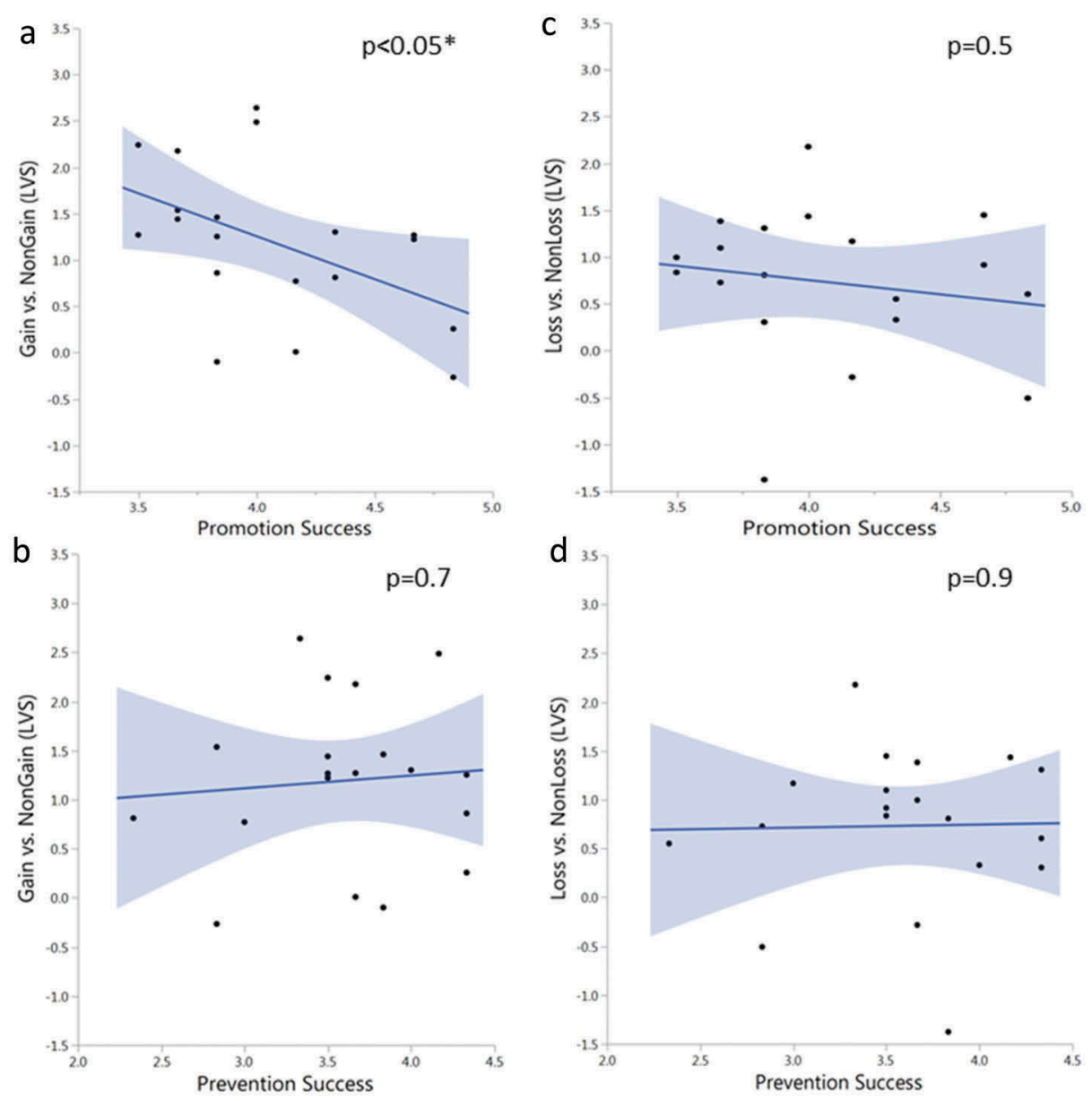

Figure 3. Regulatory focus and ventral striatum response to gain or loss cues. Promotion orientation was selectively associated with ventral striatum response to gains, while as expected, no relationship was observed between prevention orientation and ventral striatum response. Specifically, (a) promotion success scores was negatively associated with left ventral striatum response to gain cues relative to nongain cues $(b=-0.481, p=0.037)$. (b) Prevention success scores did not correlate with ventral striatum response to gain cues relative to nongain cues $(b=0.085, p=0.728)$. Neither promotion success scores (c) $(b=-0.164, p=0.501)$ nor prevention success scores $(\mathrm{d})(b=0.021, p=0.931)$ were associated with ventral striatum response to loss cues relative to nonloss cues.

to have been driven by the $\$ 5$, highest-value cues (Figure 4). Interestingly, follow-up analyses found that promotion success also correlated with VS response to the $\$ 0$ cues relative to the no-response cues [LVS: $F(1$, 17) $=4.577, p=0.047, b=-0.461$; RVS: $F(1,17)=7.210$ $p=0.016, b=-0.546]$, indicating lower VS response at baseline. These effects were not observed for prevention success [LVS: $F(1,17)=0.106, p=0.748, b=0.079$; RVS: $F(1,17)=0.734, p=0.404 b=0.203$ ].

Results did not change significantly after controlling for sex and race.

\section{Discussion}

This study used the well-validated MID task to assess the role of individual differences in regulatory focus in fundamental processes associated with reward. The study is the first to investigate the association between individual differences in regulatory focus (measured via questionnaire) and neural responses during a reward task. RFT predicts that promotion orientation constitutes a "psychological situation" in which the individual seeks to maximize positive outcomes without concern for errors or losses (Lewin, 1946). And in fact, we did observe that VS activation was predicted by individual differences in strength of promotion orientation, but not by strength of prevention orientation. However, the results revealed an inverse association-that is, individuals with a more dominant promotion orientation manifested decreased VS responsiveness to reward cues. Specifically, we found that greater self-reported promotion success was associated with decreased VS response to gain cues, relative to a no-value control condition. The observed association was unique to 


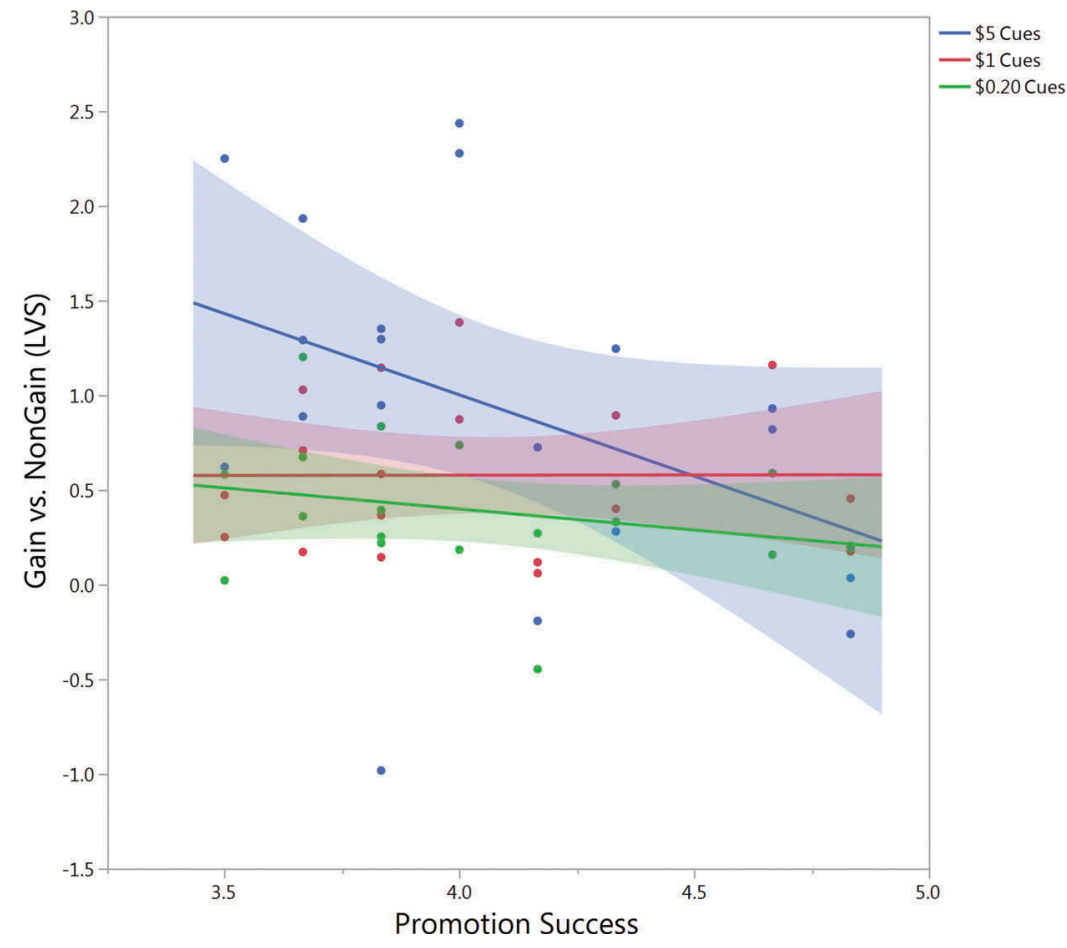

Figure 4. Regulatory focus and ventral striatum response to high- and low-value cues. The negative correlation between promotion orientation and ventral striatum response appears to have been driven primarily by the high-value, $\$ 5$, cues.

individual differences in promotion orientation and trials signaling opportunity for gain as there were no significant associations between promotion success and VS response to loss avoidance or with prevention orientation and any VS response to gain or loss avoidance. We did not find evidence that framing the task in promotion versus prevention terms had an impact above and beyond the demands inherent in the task itself, which is likely due to the highly salient nature of the task stimuli.

The present study highlights that promotion is uniquely associated with responding in the VS in the context of rewarding stimuli. Such a discriminant pattern of findings is consistent with previous studies comparing promotion and prevention, which have proposed that the two motivational systems are characterized by different strategies and means-with promotion-oriented individuals being driven by reward-seeking eagerness, and prevention-oriented individuals being primarily driven by caution and vigilance (Förster, Higgins, \& Idson, 1998; Higgins et al., 2001). The behavioral literature comparing the goalseeking characteristics of promotion-oriented and prevention-oriented individuals may be useful in disambiguating the seemingly paradoxical inverse association between promotion orientation and VS activation.

How can the attenuated VS response to a rewardbased task among individuals reporting higher degrees of promotion goal pursuit success be explained? There are potential explanations centered on the neural processes as well as on the psychological processes associated with them. One possible interpretation is consistent with a reward deficiency model (Blum et al., 2000), whereby individuals with greater promotion orientation typically have a relatively decreased neural response to rewards and therefore seek greater levels of reward to compensate for the attenuated responses. An analogous interpretation has been proposed to explain blunted VS responses during the MID task associated with individual differences in impulsivity and with risk for addiction (Andrews et al., 2011; Scheres, Milham, Knutson, \& Castellanos, 2007), and promotion orientation has previously been associated with impulsive behaviors such as impulsive eating (Florack, Friese, \& Scarabis, 2010; Sengupta \& Zhou, 2007). In support of this interpretation, we found decreased VS response even for our no-value baseline condition relative to the no-response control condition, suggesting hypoactive VS response when faced with any motivated context.

What might the self-regulation literature offer in terms of accounting for this inverse association? One consideration in interpreting the results is that the neural response may have been influenced by the predetermined rate of successful hits, which was controlled to approximate $66 \%$ in the present study. While this 
rate has been implemented successfully in previous studies using the MID task to elicit reward-based activation (Andrews et al., 2011; Knutson, Bhanji, Cooney, Atlas, \& Gotlib, 2008; Wu et al., 2014), it is possible that $66 \%$ may be experienced by promotion-oriented individuals as an unacceptably low reinforcement rate, which, incidentally, was reported informally by several participants. If such were the case, then the more promotion-oriented a participant was, the greater the likelihood that she or he would experience the MID task more in terms of failure than success. And in fact, individuals with high levels of self-reported promotion success are frequently both optimistic and overconfident (Zou, Scholer, \& Higgins, 2014). As such, they would be likely to experience a $66 \%$ hit rate as disappointing and would have expected themselves to do much better. If indeed this was the "psychological situation" for our promotion-oriented participants, then the inverse association of chronic promotion success with attenuated VS responses would be expected, particularly when the task itself was framed in promotion terms (Bryant \& Dunford, 2008). In support of this interpretation, the effects were observed specifically for the high-value cues, which were likely to have been the most highly motivating for promotion-oriented individuals. This perspective reveals the "flip side" of a dominant promotion orientation-when reward is easily available, individuals pursue goals vigorously and experience high levels of appetitive motivation and positive affect; however, when reward is perceived as available at a rate that is not a sufficient match for the individual's expectations, then the association with the reward cue may decrease or could even come to signal likely impending failure.

Other trends within the RFT literature help to elucidate the inverse association that was observed. Previous studies have noted that for individuals high in promotion orientation, large rewards are needed to elicit subjective ratings of progress (Zou et al., 2014). Additionally, given that promotion and prevention are associated with distinct emotions in the face of negative feedback (Molden et al., 2008), the absolute hit rate that we used may be an important factor in eliciting the specific (i.e., discriminant but inverse) neural activation pattern observed in this study. From the perspective of RFT, and its precursor, self-discrepancy theory (Higgins, 1987), it is important to consider that motivational, affective, and behavioral responses to social stimuli (including opportunities for reward) are determined both by the system that is engaged at any point in time-that is, promotion or prevention-and by the individual's perceived sense of success versus failure (rather than any absolute value or probability of reward). These interactions may furthermore be complicated by individual differences in genotype, which was the case in a recent study of self-discrepancy related striatal response predicting depressive symptoms (Shi et al., 2016).

Another potential explanation based on the self-regulation literature comes from a related theory, regulatory fit theory (Higgins, 2000). In brief, this theory proposes that motivational strength will be enhanced, or diminished, when the experience of working toward a goal sustains, or disrupts, the individual's regulatory orientation. As was indicated by the spontaneous comments of several participants, the $66 \%$ average success rate for reward cues may have been experienced as insufficient or frustrating, which would have the effect of creating a sense of non-fit that would reduce rather than enhance motivation to obtain reward (Spiegel, Grant-Pillow, \& Tory Higgins, 2004). This explanation also is consistent with the observation that the inverse correlation between promotion motivation and VS activation in response to reward cues was strongest for the highest-value cues, which presumably would have the greatest motivational significance for participants. A lack of fit between the reward contingencies and a dominant promotion orientation could account for the apparent decrease in VS engagement, particularly in response to the highest-value cues. Based on our behavioral results indicating that participants were engaged in the task throughout the experiment, we do think that the task was sufficiently motivating, but may not have been sufficiently rewarding for those with high promotion orientation. RFT suggests that promotion-oriented individuals increase their effort in the face of promotion failure (Crowe \& Higgins, 1997), and only after prolonged negative feedback will stop responding. In this case, we think that the degree of promotion failure was enough to be sufficiently motivating, but perhaps not rewarding.

The present study expands our understanding of motivation and reward by investigating the association between the psychological construct of self-regulation and neural responses to anticipated gain and loss within a robust and well-validated neuroimaging task. The results are informative and challenging, but do have several limitations. One limitation of the present study is that, because our primary intent was to examine neural responses to reward cues rather than behavioral responses to those cues, the task we selected was not optimal for analyzing behavioral data-for example, reaction times were only recorded when subjects responded during the target presentation. Future studies could incorporate modifications to the basic MID task to better compare behavioral and imaging outcomes in order to 
clarify the observed inverse association between promotion orientation and VS response to gain cues. Another consideration for future investigations is the predetermined rate of accuracy on the task. As mentioned, task difficulty was set $a$ priori so that subjects would achieve an approximately $66 \%$ overall success rate. Next steps could involve varying the hit rate (both overall and within condition) in order to establish how the success rate interacts with regulatory focus orientation on a trial-bytrial basis. Third, the promotion versus prevention instructional framing was found to have little impact on the results and may have been too subtle of a manipulation within this particular task. Future work could therefore employ other variations of promotion and prevention framing to manipulate state levels of promotion or prevention orientation. Fourth, a critical mediating variable within RFT (as discussed above) is the individual's perception of relative success versus failure, within either the promotion or prevention domain. As such, it would be useful to incorporate assessment of participants' self-perceived overall rate of success and summary evaluation of whether or not they are "making good things happen" (promotion) or "keeping bad things from happening" (prevention).

These limitations notwithstanding, the present study provides a glimpse into potential mechanisms underlying different behavioral responses that follow from distinct regulatory focus styles. The results expand our understanding of the relationship between regulatory focus and reward, which could ultimately help to better individually tailor reward structures so as to optimally motivate people on an individual basis.

\section{Acknowledgments}

We would like to thank Elizabeth Doody and Carolina Lyrio for help with data collection and Charlene Wu for advice on data analyses. We would also like to thank Brian Knutson for sharing his automated MID task program.

\section{Disclosure statement}

No potential conflict of interest was reported by the authors.

\section{Funding}

This work was supported by a National Institute on Drug Abuse (NIDA) Center [grant number P30 DA023026]; and by a grant to TJS and ARH from the National Institutes of Health Common Fund and managed by the OD/Office of Strategic Coordination (OSC) [grant number R01 DA031579]; MAS is supported by a National Science Foundation Graduate Research Fellowship; JLH was supported by postdoctoral fellowships provided by the National Institute of Child Health and Human Development [grant number T32-HD07376-25] through the Center for Developmental Science, University of North Carolina at Chapel Hill, as well as the National Institute on Drug Abuse [grant number P30-DA023026-08].

\section{ORCID}

Matthew A. Scult (DD http://orcid.org/0000-0001-5554-8186

\section{References}

Amodio, D. M., Shah, J. Y., Sigelman, J., Brazy, P. C., \& HarmonJones, E. (2004). Implicit regulatory focus associated with asymmetrical frontal cortical activity. Journal of Experimental Social Psychology, 40(2), 225-232. doi:10.1016/S0022-1031(03)00100-8

Andrews, M. M., Meda, S. A., Thomas, A. D., Potenza, M. N., Krystal, J. H., Worhunsky, P., \& Pearlson, G. D. (2011). Individuals family history positive for alcoholism show functional magnetic resonance imaging differences in reward sensitivity that are related to impulsivity factors. Biological Psychiatry, 69(7), 675-683. doi:10.1016/j.biopsych.2010.09.049

Beck, A., Schlagenhauf, F., Wüstenberg, T., Hein, J., Kienast, T., Kahnt, T., \& Wrase, J. (2009). Ventral striatal activation during reward anticipation correlates with impulsivity in alcoholics. Biological Psychiatry, 66(8), 734-742. doi:10.1016/j. biopsych.2009.04.035

Blum, K., Braverman, E. R., Holder, J. M., Lubar, J. F., Monastra, V. J., Miller, D., \& Comings, D. E. (2000). The reward deficiency syndrome: A biogenetic model for the diagnosis and treatment of impulsive, addictive and compulsive behaviors. Journal of Psychoactive Drugs, 32(sup1), 1-112. doi:10.1080/02791072.2000.10736099

Boldero, J. M., \& Higgins, E. T. (2011). Regulatory focus and political decision making: When people favor reform over the status quo. Political Psychology, 32(3), 399-418. doi:10.1111/j.1467-9221.2010.00814.x

Bryant, P., \& Dunford, R. (2008). The influence of regulatory focus on risky decision-making. Applied Psychology, 57(2), 335-359. doi:10.1111/j.1464-0597.2007.00319.x

Crowe, E., \& Higgins, E. (1997). Regulatory focus and strategic inclinations: Promotion and prevention in decision-making. Organizational Behavior and Human Decision Processes, 69 (2), 117-132. Retrieved from http://www.sciencedirect.com/ science/article/pii/S0749597896926758

Eddington, K. M., Dolcos, F., Cabeza, R., Krishnan, K. R., \& Strauman, T. J. (2007). Neural correlates of promotion and prevention goal activation: An fMRI study using an idiographic approach. Journal of Cognitive Neuroscience, 19(7), 1152-1162. doi:10.1162/jocn.2007.19.7.1152

Florack, A., Friese, M., \& Scarabis, M. (2010). Regulatory focus and reliance on implicit preferences in consumption contexts. Journal of Consumer Psychology, 20(2), 193-204. doi:10.1016/j.jcps.2010.02.001

Förster, J., Higgins, E. T., \& Bianco, A. T. (2003). Speed/accuracy decisions in task performance: Built-in trade-off or separate strategic concerns? Organizational Behavior and Human Decision Processes, 90(1), 148-164. doi:10.1016/S0749-5978 (02)00509-5

Förster, J., Higgins, E. T., \& Idson, L. C. (1998). Approach and avoidance strength during goal attainment: Regulatory 
focus and the "goal looms larger" effect. Journal of Personality and Social Psychology, 75(5), 1115-1131. Retrieved from http://www.ncbi.nlm.nih.gov/pubmed/ 9866180

Goetz, E. L., Hariri, A. R., Pizzagalli, D. A., \& Strauman, T. J. (2013). Genetic moderation of the association between regulatory focus and reward responsiveness: A proof-ofconcept study. Biology of Mood \& Anxiety Disorders, 3(1), 3. doi:10.1186/2045-5380-3-3

Higgins, E. T. (1987). Self-discrepancy: A theory relating self and affect. Psychological Review, 94(3), 319. doi:10.1037/ 0033-295X.94.3.319

Higgins, E. T. (1997). Beyond pleasure and pain. American Psychologist, 52(12), $1280 . \quad$ doi:10.1037/0003066X.52.12.1280

Higgins, E. T. (1998). Promotion and prevention: Regulatory focus as a motivational principle. Advances in Experimental Social Psychology, 30, 1-46.

Higgins, E. T. (2000). Making a good decision: Value from fit. The American Psychologist, 55(11), 1217-1230. doi:10.1037/ 0003-066X.55.11.1217

Higgins, E. T., Friedman, R., Harlow, R. E., Idson, L. C., Ayduk, O. N., \& Taylor, A. (2001). Achievement orientations from subjective histories of success: Promotion pride versus prevention pride. European Journal of Social Psychology, 31, 3-23. Retrieved from http://onlinelibrary.wiley.com/doi/10.1002/ ejsp.27/abstract

Higgins, E. T., Roney, C. J., Crowe, E., \& Hymes, C. (1994). Ideal versus ought predilections for approach and avoidance distinct self-regulatory systems. Journal of Personality and Social Psychology, 66(2), 276-286. Retrieved from http:// www.ncbi.nlm.nih.gov/pubmed/8195986

Knutson, B., Bhanji, J. P., Cooney, R. E., Atlas, L. Y., \& Gotlib, I. H. (2008). Neural responses to monetary incentives in major depression. Biological Psychiatry, 63(7), 686-692. doi:10.1016/j.biopsych.2007.07.023

Knutson, B., \& Greer, S. M. (2008). Anticipatory affect: Neural correlates and consequences for choice. Philosophical Transactions of the Royal Society B: Biological Sciences, 363 (1511), 3771-3786. doi:10.1098/rstb.2008.0155

Knutson, B., Westdorp, A., Kaiser, E., \& Hommer, D. (2000). FMRI visualization of brain activity during a monetary incentive delay task. Neurolmage, 12(1), 20-27. doi:10.1006/nimg.2000.0593

Lanaj, K., Chang, C.-H. D., \& Johnson, R. E. (2012). Regulatory focus and work-related outcomes: A review and meta-analysis. Psychological Bulletin, 138(5), 998-1034. doi:10.1037/a0027723

Lewin, K. (1946). Behavior and development as a function of the total situation. In L. Carmichael (Ed.), Manual of child psychology (pp. 238-305). New York, NY: John Wiley \& Sons.

Molden, D. C., Lee, A. Y., \& Higgins, E. T. (2008). Motivations for promotion and prevention. In J. Shah \& W. Gardner (Eds.),
Handbook of motivation science (pp. 169-187). New York, NY: Guilford Press.

Neubert, M. J., Kacmar, K. M., Carlson, D. S., Chonko, L. B., \& Roberts, J. A. (2008). Regulatory focus as a mediator of the influence of initiating structure and servant leadership on employee behavior. The Journal of Applied Psychology, 93 (6), 1220-1233. doi:10.1037/a0012695

Scheres, A., Milham, M. P., Knutson, B., \& Castellanos, F. X. (2007). Ventral striatal hyporesponsiveness during reward anticipation in attention-deficit/hyperactivity disorder. Biological Psychiatry, 61(5), 720-724. doi:10.1016/j. biopsych.2006.04.042

Sengupta, J., \& Zhou, R. (2007). Understanding impulsive eaters' choice behaviors: The motivational influences of regulatory focus. Journal of Marketing Research, 44(2), 297-308. doi:10.1509/jmkr.44.2.297

Shah, J., Higgins, E. T., \& Friedman, R. S. (1998). Performance incentives and means: How regulatory focus influences goal attainment. Journal of Personality and Social Psychology, 74(2), 285-293. Retrieved from http://www. ncbi.nlm.nih.gov/pubmed/9491583

Shi, Z., Ma, Y., Wu, B., Wu, X., Wang, Y., \& Han, S. (2016). Neural correlates of reflection on actual versus ideal self-discrepancy. Neurolmage, 124, 573-580. doi:10.1016/j. neuroimage.2015.08.077

Spiegel, S., Grant-Pillow, H., \& Tory Higgins, E. (2004). How regulatory fit enhances motivational strength during goal pursuit. European Journal of Social Psychology, 34(1), 39-54. doi:10.1002/ejsp.180

Strauman, T. J. (1996). Stability within the self: A longitudinal study of the structural implications of self-discrepancy theory. Journal of Personality and Social Psychology, 71(6), 1142-1153. Retrieved from http://www.ncbi.nlm.nih.gov/ pubmed/8979383

Strauman, T. J., Detloff, A. M., Sestokas, R., Smith, D. V., Goetz, E. L., Rivera, C., \& Kwapil, L. (2013). What shall I be, what must I be: Neural correlates of personal goal activation. Frontiers in Integrative Neuroscience, 6(January), 123. doi:10.3389/fnint.2012.00123

Vieth, A. Z., Strauman, T. J., Kolden, G. G., Woods, T. E., Michels, J. L., \& Klein, M. H. (2003). Self-system therapy (SST): A theory-based psychotherapy for depression. Clinical Psychology: Science and Practice, 10(3), 245-268. doi:10.1093/clipsy.bpg023

Wu, C. C., Samanez-Larkin, G. R., Katovich, K., \& Knutson, B. (2014). Affective traits link to reliable neural markers of incentive anticipation. Neurolmage, 84, 279-289. doi:10.1016/j.neuroimage.2013.08.055

Zou, X., Scholer, A. A., \& Higgins, E. T. (2014). In pursuit of progress: Promotion motivation and risk preference in the domain of gains. Journal of Personality and Social Psychology, 106(2), 183-201. doi:10.1037/a0035391 